Research Article

\title{
Seismic Vibration Mitigation of a Cable-Stayed Bridge with Asymmetric Pounding Tuned Mass Damper
}

\author{
Peng Zhang $\mathbb{D}^{1},{ }^{1}$ Jie Tan $\mathbb{D}^{\mathrm{D}},{ }^{2,3}$ Haitao Liu $\mathbb{D}^{1},{ }^{1}$ Gang Yang $\mathbb{D}^{1},{ }^{1}$ and Chunyi Cui $\mathbb{D}^{1}$ \\ ${ }^{1}$ Institute of Road and Bridge Engineering, Dalian Maritime University, Dalian 116023, China \\ ${ }^{2}$ Hubei Key Laboratory of Earthquake Early Warning, Institute of Seismology, China Earthquake Administration, \\ Wuhan 430071, China \\ ${ }^{3}$ Wuhan Institute of Earthquake Engineering, Wuhan 430071, China \\ Correspondence should be addressed to Chunyi Cui; cuichunyi@dlmu.edu.cn
}

Received 21 December 2020; Revised 27 March 2021; Accepted 19 April 2021; Published 29 April 2021

Academic Editor: Hao Wang

Copyright (c) 2021 Peng Zhang et al. This is an open access article distributed under the Creative Commons Attribution License, which permits unrestricted use, distribution, and reproduction in any medium, provided the original work is properly cited.

\begin{abstract}
In order to mitigate the seismic response of a cable-stayed bridge, a new type damping device named asymmetric pounding tuned mass damper (APTMD) is developed in this paper on the basis of the traditional symmetric pounding tuned mass damper. The novel APTMD has three parameters to be determined: the left-side gap, the right-side gap, and the frequency ratio. A numerical model of the APTMD damping system is established with consideration of both the computational efficiency and accuracy to enable the parametric optimization of the damper. The numerical model is based on a simplified model of the cable-stayed bridge and a nonlinear pounding force model. The genetic algorithm is utilized for the optimization of the damper. Afterwards, the cablestayed bridge is subjected to 20 recorded ground motions to evaluate the vibration control effectiveness of the APTMD. Four systems are considered: (1) without dampers; (2) with a TMD; (3) with a PTMD; and (4) with an APTMD. Time history analysis reveals the following: (1) those dampers can all effectively suppress the vibration of the bridge and (2) the vibration control effectiveness of the APTMD is slightly better than the TMD and the PTMD.
\end{abstract}

\section{Introduction}

Cable-stayed bridges, typical long-span structures used in modern traffic and transportation systems, are featured by their large flexibility and low damping. During the past decades, structural damage induced by earthquakes has been extensively reported and investigated [1-4]. Therefore, it is of great necessity to reduce the seismic responses of a bridge and so as to improve its safety and reliability.

The seismic isolation technique is one of the most efficient vibration control techniques and its effectiveness has been verified by numerous numerical simulations and experimental investigations. The seismic isolation technique often employs flexible bearings to isolate the superstructure from its foundations and consequently interrupt the energy transfer between the superstructure and substructure. The most commonly adopted base isolators include lead rubber bearings (LRB) and friction pendulum systems (FPS), both exhibiting large vertical stiffness and low horizontal stiffness. Due to the large lateral flexibility, the isolating system often suffers from large displacements under earthquakes. Therefore, additional damping was introduced to the isolating systems to reduce the displacement of the isolators. Peng and Huang proposed to implant permanent magnets and elastomer fillings to the regular isolators. This new isolator was named the implant-magnetic bearing (IMB) and had been proved effective in mitigating the story accelerations and interstory drifts via both numerical studies [5] and experimental tests $[6,7]$. Zheng [8] introduced the shape memory alloys (SMA) into the LRB system and proposed a superelasticsliding lead rubber bearing (SSLRB) isolation system. Compared with the conventional LRBs, the SSLRB further reduce the residual displacement and the seismic demand of the piers. De Domenico et al. [9]combined the lowfriction curved surface sliders (CSSs) with SMA gap 
dampers. The combined isolating system is featured by the negligible residual displacement under small earthquakes and reduced displacement demand under large earthquakes. Wang et al. [10] proposed a novel self-centering (SC) base isolating system by incorporating SMA U-shaped dampers (SMA-UD). The superelasticity behavior of the SMA-UDs provides sufficient energy dissipation and excellent SC force. Additionally, the hysteresis characteristics of the SMA-UD are nearly isotropic, indicating that these isolators can be effective in any horizontal direction. Another drawback of the FPS system is that the sliding friction coefficient is sensitive to the surrounding temperatures and may lose recentering capability at low temperature. Zheng et al. [11] proposed a shape memory alloys (SMA) based FPS system to address this issue. Analytical results demonstrate that the residual displacement of the regular FPB system can be effectively reduced without significantly increasing the base forces of the bridge piers. In a following parametric study [12], the influence of the SMA wire properties on the response of the bridge to be controlled was investigated and optimal design can be obtained. A case study further demonstrated that the SMA-based FPB system can reduce the residual displacement and peak displacement when subjected to near-fault ground motions. Gur et al. [13] proposed to incorporate the base isolators with thermally modulated SMA damper, of which the temperature is altered during loading-unloading cycles to improve the energy dissipation. It is demonstrated by a numerical simulation that the thermally modulated shape memory alloy friction pendulum (tmSMA-FP) showed improved control efficiency compared with the regular FPS and SMA-FPS.

The tuned mass damper (TMD) is another commonly adapted damping device for bridge structures. In concept, the TMD is a dynamic absorber, often installed at the place of the main structure where the largest motion occurs. When the TMD is tuned to the target frequency of the main structure, it can effectively absorb the kinetic energy of the primary structure and thus reduce its vibration [14]. However, the TMD often suffers from a limited energy dissipation capacity and a relatively narrow band of effective frequency. Therefore, a variety of damping elements are introduced to the TMD to improve vibration control efficiency and robustness, such as friction dampers $[15,16]$, eddy-current components [17-20], inerters [21-24], particle dampers [25, 26], and shape memory alloys [27-29]. Most of these damping elements are expensive in cost and difficult in maintenance.

Recently, a new passive damping device named pounding tuned mass damper (PTMD) was proposed for vibration control of flexible structures such as power transmission towers [30, 31], high-rise buildings [32], subsea pipelines [33, 34], and bridges [35-37]. The PTMD consists of a tuned mass whose stroke is restrained by a pair of delimiters covered with viscoelastic materials. When the tuned mass impacts on the viscoelastic delimiter, large amounts of energy can be dissipated via collision. Therefore, the PTMD has an additional energy consumption pattern compared with a regular TMD and thus has better vibration control effectiveness. Furthermore, this additional damping mechanism can also improve the robustness of the PTMD. Even if the PTMD is off-tuned from the target frequency by $15 \%$, it still can effectively mitigate the vibration of the primary structure $[33,38]$.

In early studies of the PTMD [30], the mass block is located in the middle of the two delimiters, which implies that the gap of the left side is the same as the right side. Parametric studies revealed that the gap is the key parameter that influences the vibration control effectiveness [39, 40]. The optimal gap is sensitive to the input amplitude and mass. To avoid the design complexity, a single-sided pounding tuned mass damper (SSPTMD) is proposed [37, 41]. In the SSPTMD, the mass block is placed aside the delimiter, which means that the gap equals zero. The frequency of the SSPTMD is tuned to half of the value of the target frequency to achieve the optimal design. Numerical studies and experimental results also validated the effectiveness of the SSPTMD.

With the inspiration of the SSPTMD, a novel damper called asymmetric pounding tuned mass damper (APTMD) is proposed in this paper. Compared with the former symmetric PTMD, the two gaps of the APTMD can be set to different values. Additionally, the frequency ratio, which is defined as the frequency of the damper over that of the primary structure, is another parameter to be determined. In order to achieve the optimal vibration mitigation effectiveness for a realistic bridge, the genetic algorithm (GA) is employed, with the left-side gap, right-side gap, and frequency ratio defined as the optimal variables and the average value of dynamic responses under 20 ground motions taken as the objective function. Even though the finite element (FE) model of the cable-stayed bridge equipped with an APTMD can be established in ANSYS, it is time-consuming to perform a time history analysis of this numerical model. Therefore, a simplified model of the bridge is developed and utilized to calculate the fitness of each individual in the GA optimization process. Finally, a time history analysis is conducted on the FE model of the cable-stayed bridge damped by the optimized APTMD. A TMD and a PTMD with the same mass ratio are also attached to the bridge to compare their damping effect with the APTMD.

The remainder of this paper is arranged as follows: in Section 2, the damping mechanism of the APTMD will be further explained by comparison with the classical TMD and the previously proposed symmetric PTMD. Motion equations of the APTMD damping system will be established on the basis of a nonlinear pounding force model in MATLAB/Simulink environment. Afterwards, a simplified model of a real cable-stayed bridge is established in Section 3. Optimal design of the APTMD will be achieved using the genetic algorithm in Section 4. Then, in Section 5, the dynamic responses of the bridge equipped with optimal APTMD, former PTMD, and traditional TMD will be compared to evaluate the performance of the proposed APTMD. Finally, this paper concludes with a discussion of the overall results and suggestion for future studies. 


\section{Development of APTMD Damping System}

2.1. Introduction of APTMD. In order to demonstrate the damping mechanism of the proposed APTMD, the schematics of the classical TMD, the previously proposed symmetric PTMD, and the APTMD, as well as the undamped system, are compared in Figure 1. In Figure 1(a), a mass block, $m_{1}$, which is connected to the base by a spring, $k_{1}$, and a dashpot, $c_{1}$, represents the primary structure with being controlled. $x_{1}$ denotes the displacement of $m_{1}$.

In Figure 1(b), an auxiliary mass, $m_{2}$, is connected to $m_{2}$ by a spring, $k_{2}$, and a dashpot $c_{2}$, composing a classical TMD. If optimally designed, the additional mass, $m_{2}$, can generate an initial force toward the equilibrium position to damp the oscillation of the primary structure $m_{1}$. However, the classical TMD suffers a deterioration in vibration control effectiveness when its parameters shift away from the optimal values. Additionally, the added mass often has an overlarge stroke, causing impacts between the added mass and the primary structure, which makes the TMD not applicable for structures with confined space. Therefore, the PTMDs are proposed to address these issues.

Figure 1(c) illustrates the previously proposed PTMD, which can be regarded as a restricted TMD. In the PTMD damping system, the motions of the additional mass $m_{2}$ are restrained within a range of two delimiters (as illustrated by the two blue triangles in Figure 1(c)). The delimiters are covered with viscoelastic materials for two purposes: firstly, to dissipate the kinetic energy when $m_{2}$ collides with the delimiter and, secondly, to reduce the noise and excessive acceleration induced by the collision. In Figure 1(c), $g p_{l}$ denotes the gap between the $m_{2}$ and the left delimiter, while $g p_{r}$ is the gap of the right side. In the previous PTMD, $g p_{l}$ equals $g p_{r}$. It is reported in much literature that there is an optimal gap for each given loading amplitude and mass ratio. For a severe dynamic excitation and relatively small mass ratio, a large gap shall be provided to allow for enough motion of the added mass, $m_{2}$. Otherwise, the energy dissipation during impact will be limited due to a small relative velocity between the added mass and the delimiter. However, if the gap is exceedingly large, the added mass will not impact on the two delimiters. In this case, the PTMD degrades to a spring-mass type dynamic absorber as Frahm invented in the 1900s.

Figure $1(\mathrm{~d})$ shows the proposed APTMD. The major difference between the previous PTMD and the APTMD is that the $g p_{l}$ and $g p_{r}$ can be set to different values in the APTMD, which may further improve the vibration control effectiveness of the damper. Three key parameters of the APTMD are $g p_{l}, g p_{r}$, and the frequency ratio of the APTMD over that of the primary structure. These parameters can be optimized using the genetic algorithm in this paper.

2.2. Nonlinear Pounding Force Model. Since the APTMD relies on the poundings between the added mass and the nonsymmetrically designed delimiters to dissipate energy, an accurate pounding force model is necessary to enable numerical study. In previous studies, the nonlinear pounding force model [42] based on the Hertz contact element and a nonlinear damping element has been proved to be relatively accurate and computationally efficient [30]. The mathematical expression of the pounding force is as follows:

$$
F= \begin{cases}\beta \delta^{1.5}+c \dot{\delta}, & \dot{\delta}>0, \\ \beta \delta^{1.5}, & \dot{\delta}<0,\end{cases}
$$

in which $\mathrm{F}$ denotes the nonlinear pounding force; $\delta$ and $\dot{\delta}$ are the deformation and velocity of deformation, respectively; $\beta$ is the pounding stiffness; and $c$ is the pounding damping, which can be determined by

$$
c=2 \xi \sqrt{\beta \delta^{0.5} \frac{m_{1} m_{2}}{m_{1}+m_{2}}}
$$

where $m_{1}$ and $m_{2}$ are the two colliding bodies and $\xi$ is the pounding damping ratio:

$$
\xi=\frac{9 \sqrt{5}}{2} \frac{1-e^{2}}{e(e(9 \pi-16)+16)},
$$

where $e$ is the restitution coefficient of the viscoelastic material. It can be obtained by dropping a sphere on the viscoelastic material, observing the initial height $h_{0}$ and rebound height $h_{1}$ :

$$
e=\sqrt{\frac{h_{1}}{h_{0}}}
$$

2.3. Governing Equation of APTMD Damping System. Based on the nonlinear pounding force model, the governing equations of a single degree of freedom (DOF) structure equipped with an APTMD are

$$
\begin{aligned}
& {\left[\begin{array}{ll}
m_{s} & \\
& m_{d}
\end{array}\right]\left\{\begin{array}{l}
\ddot{x}_{s} \\
\ddot{x}_{d}
\end{array}\right\}+\left[\begin{array}{cc}
c_{s} & 0 \\
0 & 0
\end{array}\right]\left\{\begin{array}{l}
\dot{x}_{s} \\
\dot{x}_{d}
\end{array}\right\}} \\
& +\left[\begin{array}{cc}
k_{s}+k_{d} & -k_{d} \\
-k_{d} & k_{d}
\end{array}\right]\left\{\begin{array}{l}
x_{s} \\
x_{d}
\end{array}\right\}=-\left[\begin{array}{ll}
m_{s} & \\
& m_{d}
\end{array}\right]\left\{\begin{array}{l}
1 \\
1
\end{array}\right\} \ddot{x}_{g}+\left[\begin{array}{c}
1 \\
-1
\end{array}\right] F_{p},
\end{aligned}
$$

where $m_{s}, c_{s}$, and $k_{s}$ are the mass, damping, and stiffness of the primary structure, respectively; and $m_{d}$ and $k_{d}$ are the mass and stiffness of the APTMD. $\ddot{x}_{s}, \dot{x}_{s}$, and $x_{s}$ denote the acceleration, velocity, and displacement of the primary structure, while $\ddot{x}_{d}, \dot{x}_{d}$, and $x_{d}$ correspond to those quantities of the damper. In equation (5), $\ddot{x}_{g}$ is the recorded ground motion and $F_{p}$ is the pounding force computed by equation (1).

Here, the deformation, $\delta$, and its velocity, $\dot{\delta}$, can be obtained by the relative displacement and velocity:

$$
\begin{aligned}
& \delta= \begin{cases}x_{d}-x_{s}-g p_{r}, & x_{d}-x_{s}-g p_{r}>0, \\
\left|x_{d}-x_{s}+g p_{l}\right|, & x_{d}-x_{s}+g p_{l}<0, \\
0, & \text { otherwise, }\end{cases} \\
& \dot{\delta}=\dot{x}_{d}-\dot{x}_{s},
\end{aligned}
$$




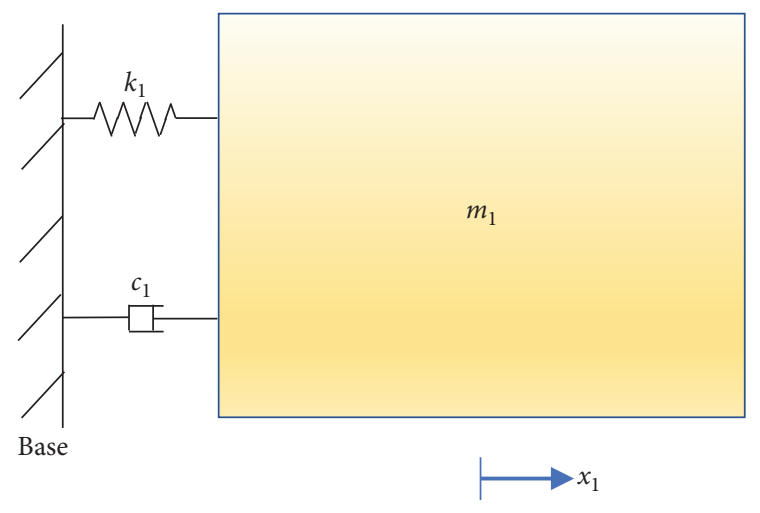

(a)

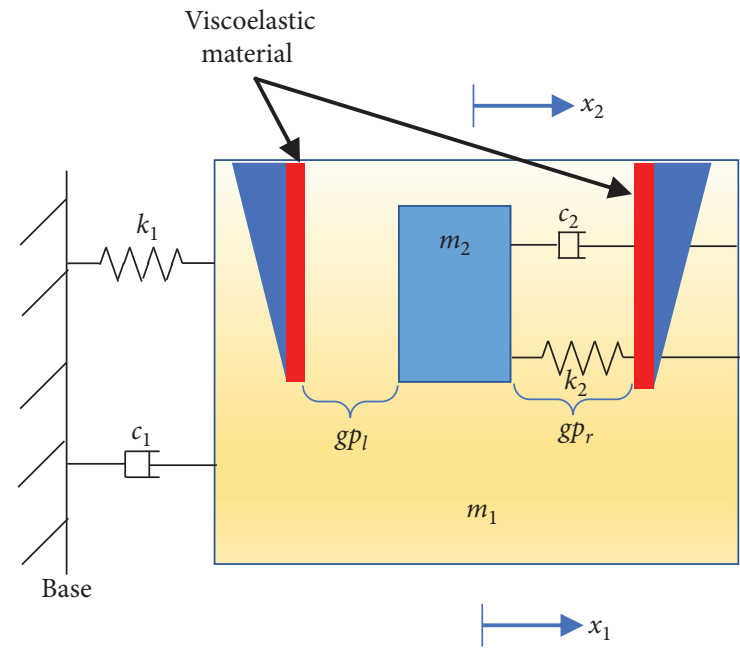

(c)

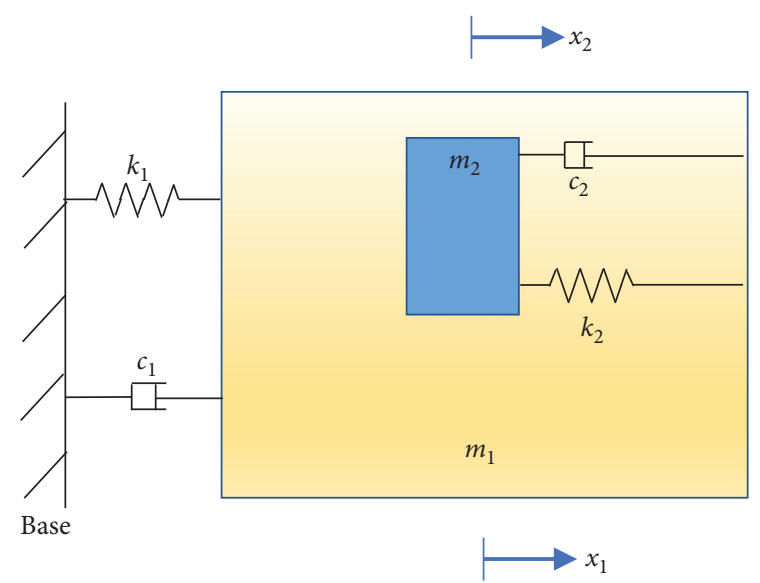

(b)

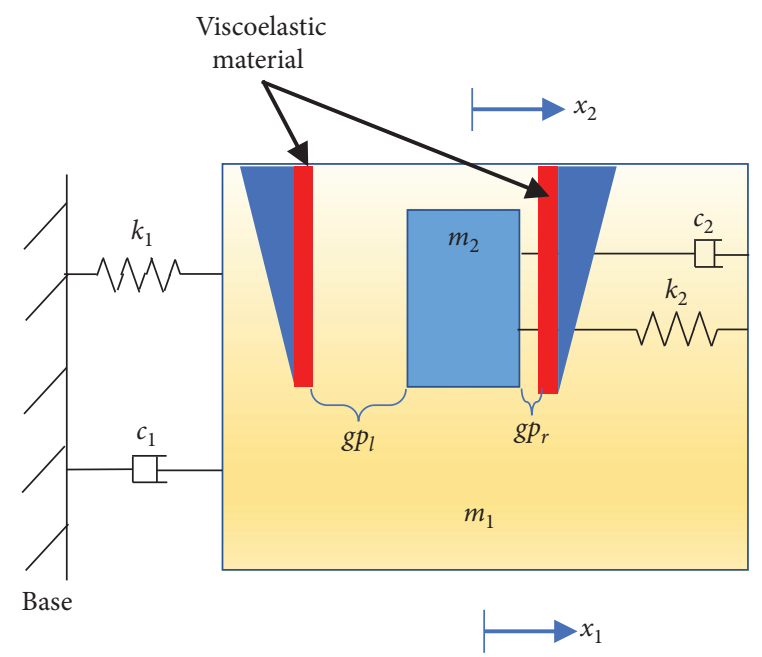

(d)

FIGURE 1: Schematics of the damping system: (a) primary structure without additional damping; (b) TMD damping system; (c) symmetric PTMD damping system; and (d) APTMD damping system.

where $g p_{l}$ and $g p_{r}$ are the gap of the left side and right side (as shown in Figure 2). In this equation, $x_{d}-x_{s}-g p_{r}>0$ implies that collisions occur on the right-side delimiter, while $x_{d}-x_{s}+g p_{l}<0$ implies that the collisions take place on the left-side delimiter. Otherwise, no collisions happen indicating $\delta=0$.

Introducing the following mass, damping, and stiffness matrices,

$$
\begin{aligned}
M & =\left[\begin{array}{ll}
m_{s} & \\
& m_{d}
\end{array}\right], \\
C & =\left[\begin{array}{ll}
c_{s} & 0 \\
0 & 0
\end{array}\right], \\
K & =\left[\begin{array}{cc}
k_{s}+k_{d} & -k_{d} \\
-k_{d} & k_{d}
\end{array}\right],
\end{aligned}
$$

and acceleration, velocity, and displacement vector,

$$
\begin{aligned}
& \ddot{X}=\left\{\begin{array}{l}
\ddot{x}_{s} \\
\ddot{x}_{d}
\end{array}\right\}, \\
& \dot{X}=\left\{\begin{array}{c}
\dot{x}_{s} \\
\dot{x}_{d}
\end{array}\right\}, \\
& X=\left\{\begin{array}{l}
x_{s} \\
x_{d}
\end{array}\right\},
\end{aligned}
$$

and vectors indicating the location of the ground motion and pounding force.

$$
\begin{aligned}
L_{e} & =\left\{\begin{array}{l}
1 \\
1
\end{array}\right\}, \\
L_{p} & =\left\{\begin{array}{c}
1 \\
-1
\end{array}\right\} .
\end{aligned}
$$

Equation (5) can be simplified as

$$
M \ddot{X}+C \dot{X}+K X=-M\left\{\begin{array}{l}
1 \\
1
\end{array}\right\} \ddot{x}_{g}+\left[\begin{array}{c}
1 \\
-1
\end{array}\right] F_{p} .
$$




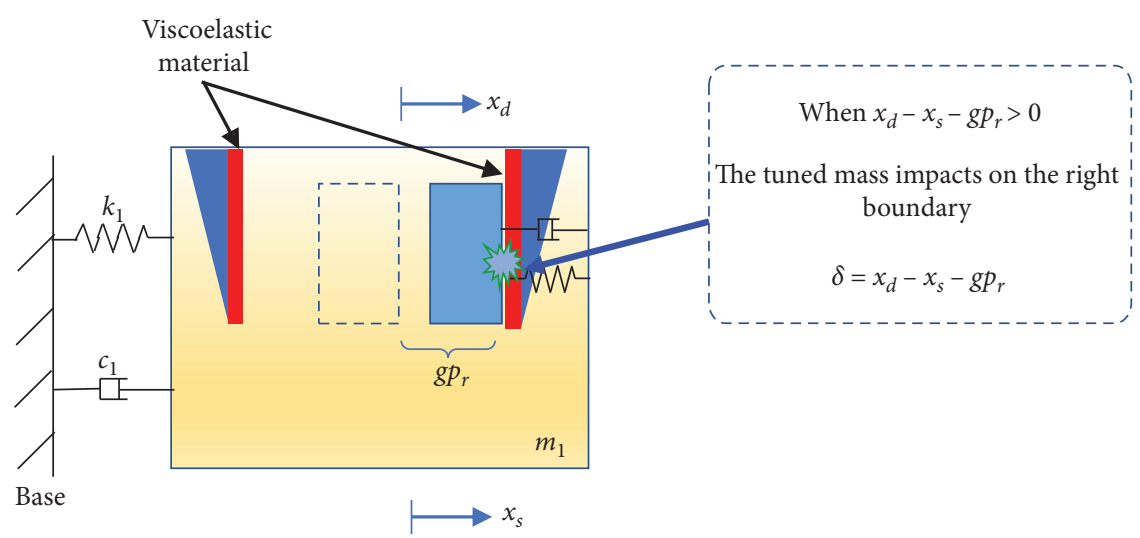

(a)

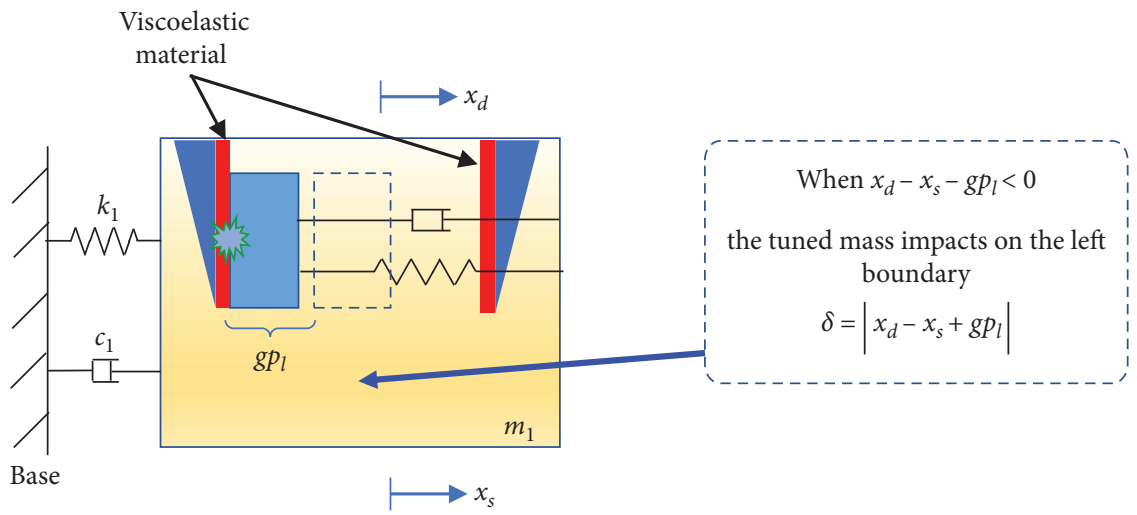

(b)

Figure 2: Determination of the impact deformation $\delta$ : (a) impacting on the right boundary and (b) impacting the left boundary.

Introducing a state vector $Z$ and the external force vector $U$, equation (10) can be expressed as

$$
Z=A Z+B \mathrm{U},
$$

where

$$
\begin{aligned}
Z & =\left\{\begin{array}{c}
X \\
\dot{X}
\end{array}\right\}, \\
\dot{Z} & =\left\{\begin{array}{c}
\dot{X} \\
\ddot{X}
\end{array}\right\}, \\
U & =\left\{\begin{array}{c}
x_{g} \\
F_{p}
\end{array}\right\}, \\
A & =\left[\begin{array}{cc}
0 & I \\
-M^{-1} K & -M^{-1} C
\end{array}\right], \\
B & =\left[\begin{array}{cc}
0 & 0 \\
-M L_{e} & L_{p}
\end{array}\right] .
\end{aligned}
$$

Equation (11) can be solved using MATLAB/Simulink environment. Figure 3 demonstrates how equation (11) is established in Simulink. The Runge-Kutta method, which is already embedded in Simulink, is employed to solve this equation. Automatic solver selection and default settings of the software were applied.

\section{Modelling of the Cable-Stayed Bridge}

In order to demonstrate the vibration control effectiveness of the APTMD, a real cable-stayed bridge located in Dalian, Liaoning, China, is selected as the primary structure to be controlled. Figure 4 and 5 illustrate the configuration and appearance of the bridge. As shown in the figures, this bridge is a typical extradosed cable-stayed bridge, with a span of $140 m+260 m+140 m$ and a width of $25 \mathrm{~m}$. The main girder is a continuous box girder with a variable cross section, supported by twin pylon and double-plane fan-type cables. The main pylon is $37.4 \mathrm{~m}$ high above the bridge deck. Concretes used for the main girder are $\mathrm{C} 55$ type concrete; those for the main pylon and piers are C50 and C40, respectively. The stay cables are made of $\Phi_{s} 15.2$ type high yield steel strand. Properties of the concretes and cables are listed in Table 1 and 2.

Every table must have a descriptive title and if numerical measurements are given, the units should be included in the column heading. Vertical rules should not be used (see Table 1). Tables should be cited consecutively in the text.

E denotes the elastic modulus of the concrete; $\mu$ is Poisson's ratio; $G$ is the shear modulus; $f_{c}$ is the design value of axial compressive strength; and $f_{t}$ is the design value of axial tensile strength. 


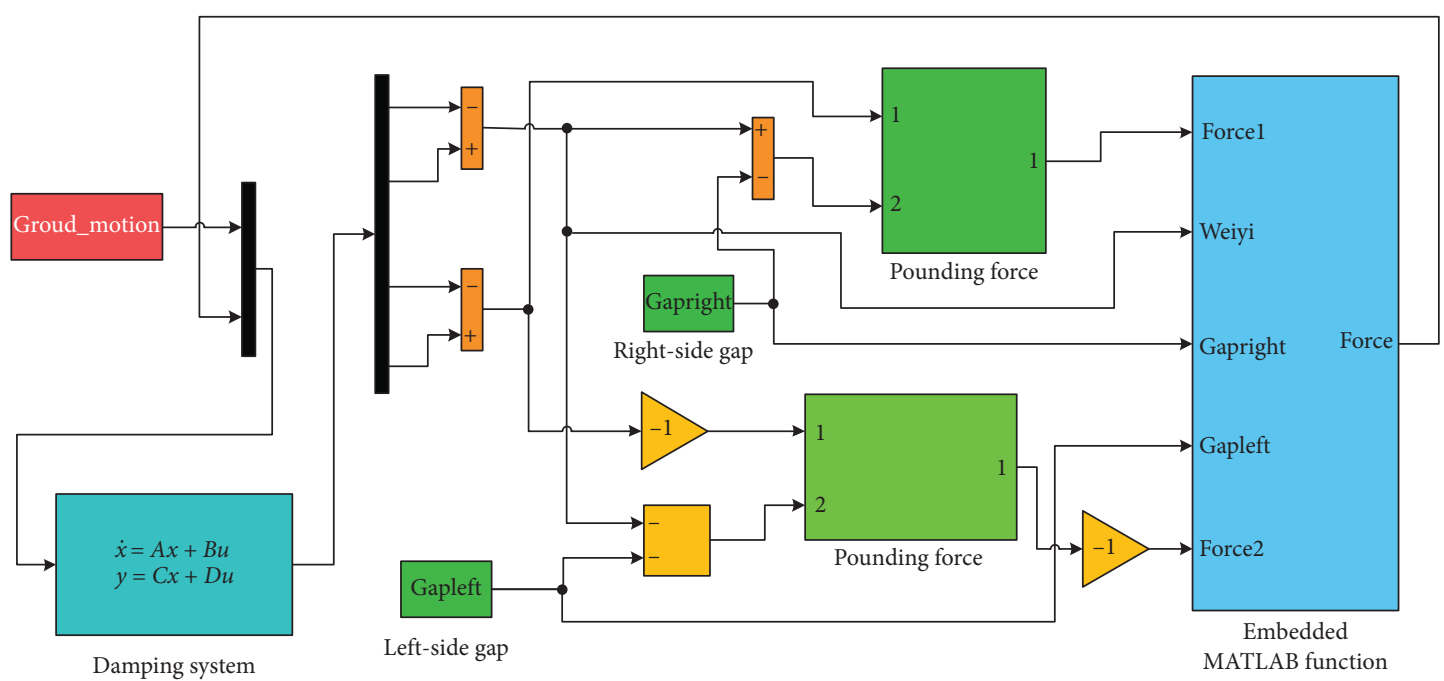

(a)

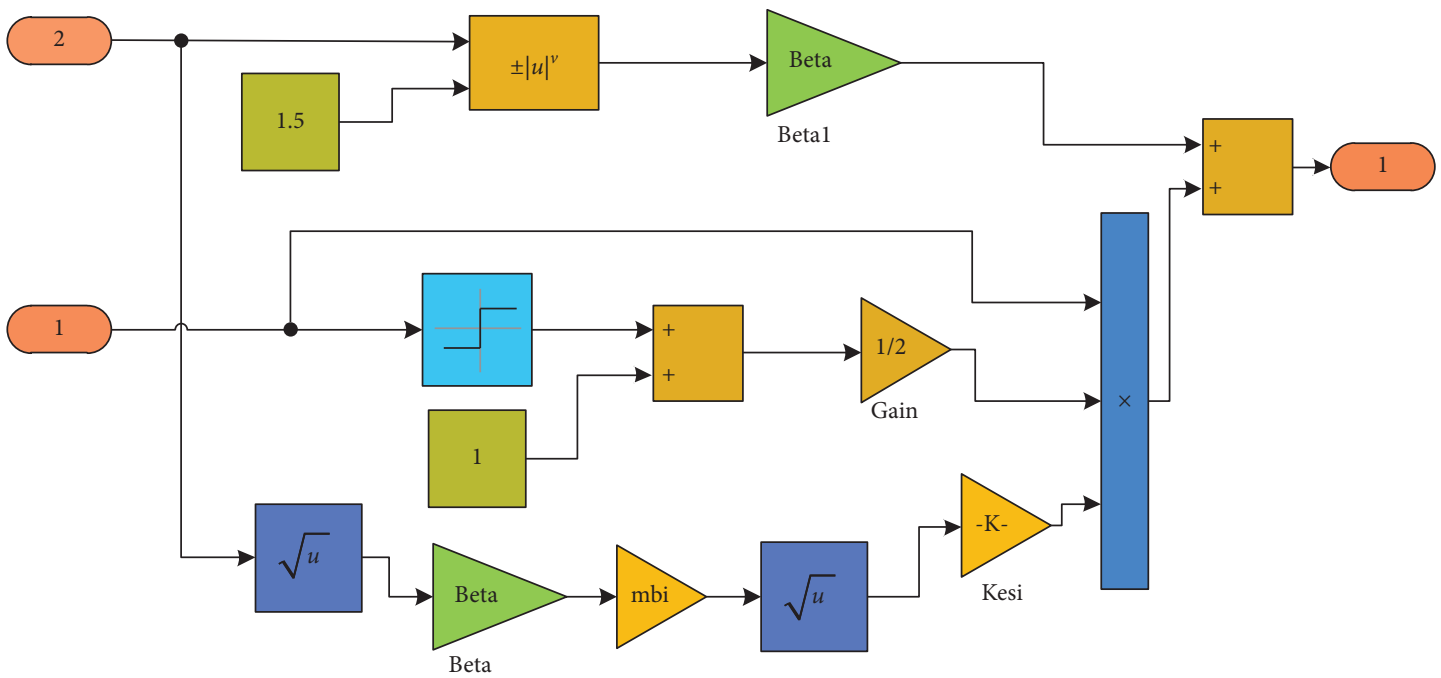

(b)

Figure 3: Model of APTMD damping system established in Simulink: (a) SDOF structure controlled by an APTMD and (b) subsystem for calculating the pounding force.

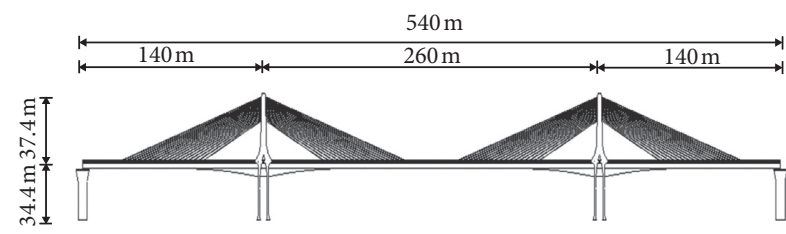

Figure 4: Configuration of Dalian Changshan Bridge.

3.1. FE Model. A finite element model of the bridge is established in ANSYS. The FE model consists of 869 nodes and 639 elements (Figure 6). The main girder, pylons, and piers are modeled using BEAM188 element; the stay cables are modeled by the LINK10 element. Furthermore, the second phase loads, that is, the loads of pavements and other facilities, are modeled by MASS 21 elements.

In order to verify the FE model, a modal analysis was conducted using Block Lanczos method. The frequencies of the first 10 orders are listed in Table 3 and the first 3 modal shapes are presented in Figure 7. Compared with the technical report of the bridge, errors of the $1^{\text {st }}$ and $2^{\text {nd }}$ order frequencies are $1.3 \%$ and $2 \%$, implying that the FE model can be used for time history analysis.

3.2. Simplified Model. Although the aforementioned nonlinear pounding force model can be simulated in ANSYS software using its APDL module, it is still time-consuming to conduct a time history analysis of the FE model of 5214 DOF. Consequently, a simplified model of the bridge is necessary to enable massive numerical studies and parametric optimization. In this paper, the bridge is represented by a concentrate mass connected to the ground with a spring and a damping element. The stiffness of the spring can be calculated using the FE model. The mass of the simplified model is $7.20 \times 10^{7} \mathrm{~kg}$ and the stiffness of the spring is 


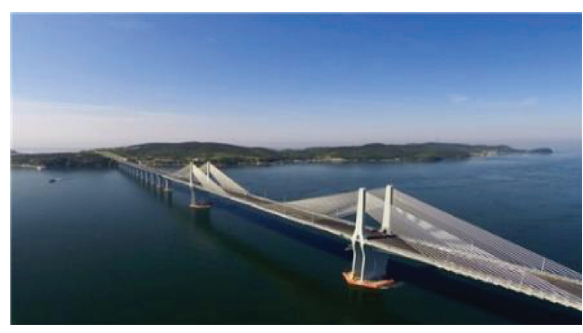

(a)

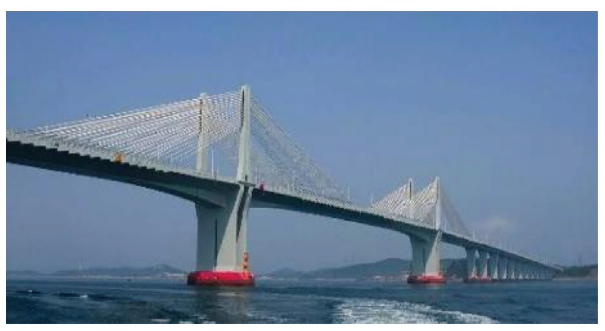

(b)

FIgure 5: On-site photographs of Dalian Changshan Bridge.

TAble 1: Properties of prestressed concrete (unit: MPa).

\begin{tabular}{lccccc}
\hline Type & $E$ & $\mu$ & $G$ & $f_{c}$ & $f_{t}$ \\
\hline C55 & 35500 & 0.2 & 14200 & 24.4 & 1.89 \\
C50 & 34500 & 0.2 & 13800 & 22.4 & 1.83 \\
C40 & 32500 & 0.2 & 13000 & 18.4 & 1.65 \\
\hline
\end{tabular}

Table 2: Properties of the strand.

\begin{tabular}{lccc}
\hline Type & Elastic modulus $(\mathrm{MPa})$ & Standard tensile strength $(\mathrm{MPa})$ & Thermal expansion coefficient $\left({ }^{\circ} \mathrm{C}\right)$ \\
\hline Strand & 195000 & 1860 & $1.2 \times 10^{-5}$ \\
\hline
\end{tabular}

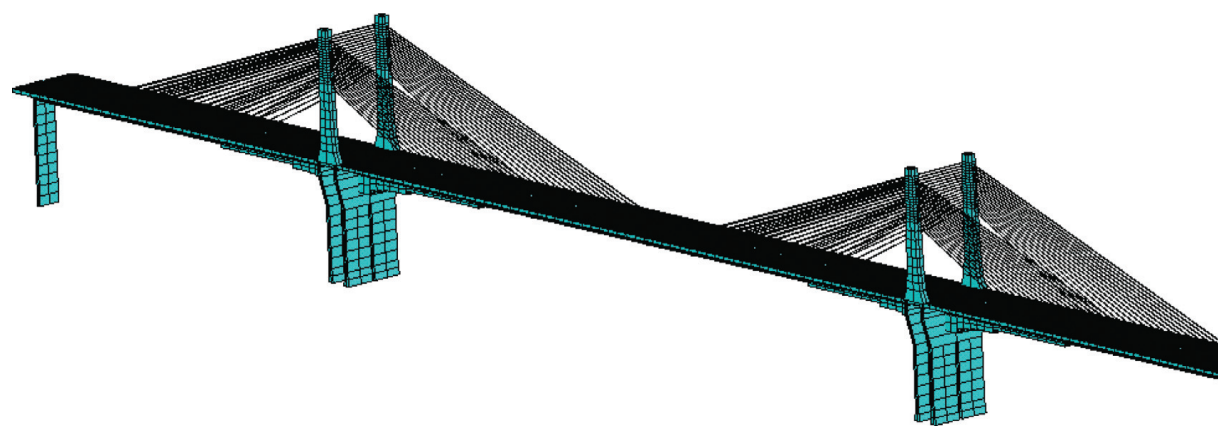

(a)

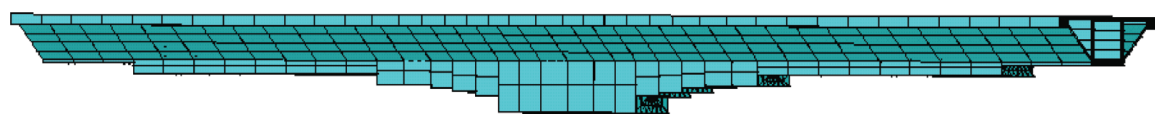

(b)

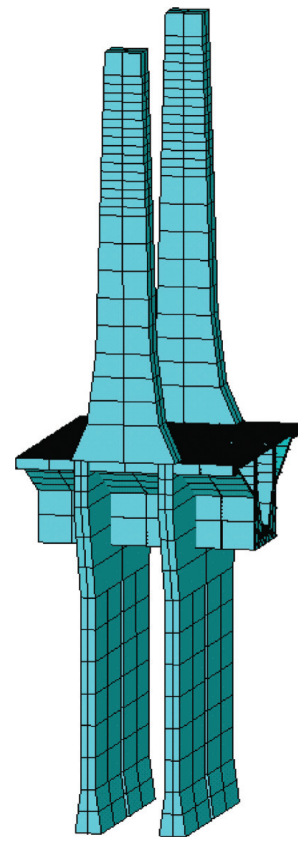

(c)

Figure 6: FE model of the bridge: (a) the whole bridge; (b) the girder; and (c) the pylon and pier. 
TABLE 3: The first 10 vibration modes of the bridge.

\begin{tabular}{lcc}
\hline Number of the mode & Frequency $(\mathrm{Hz})$ & Description of modal shape \\
\hline $1^{\text {st }}$ & 0.239 & 0.448 \\
$2^{\text {nd }}$ & 0.566 & Floating of the girder in the longitudinal direction \\
$3^{\text {rd }}$ & 0.608 & Symmetric bending of the girder in the vertical direction \\
$4^{\text {th }}$ & 0.608 & Symmetric bending of the girder in the lateral direction \\
$5^{\text {th }}$ & 0.654 & Floating of the side piers in the longitudinal direction \\
$6^{\text {th }}$ & 0.666 & Floating of the side piers in the longitudinal direction \\
$7^{\text {th }}$ & 0.680 & The tower bends asymmetrically in the lateral direction \\
$8^{\text {th }}$ & 0.815 & Bending of the girder in the vertical direction (second order) \\
$9^{\text {th }}$ & 0.815 & Symmetric bending of the girder in the lateral direction (second order) \\
$10^{\text {th }}$ & Bending of the pylon toward the inside direction
\end{tabular}

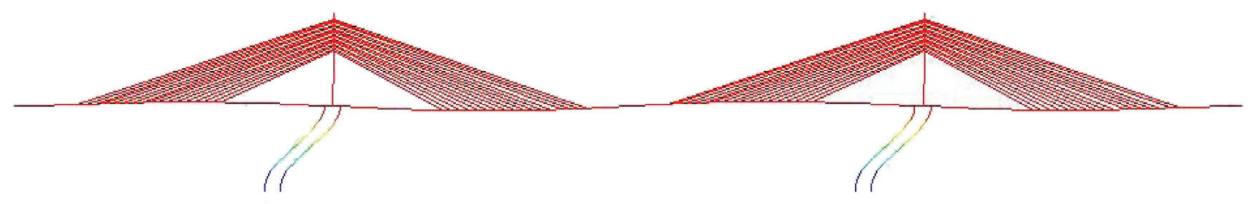

(a)

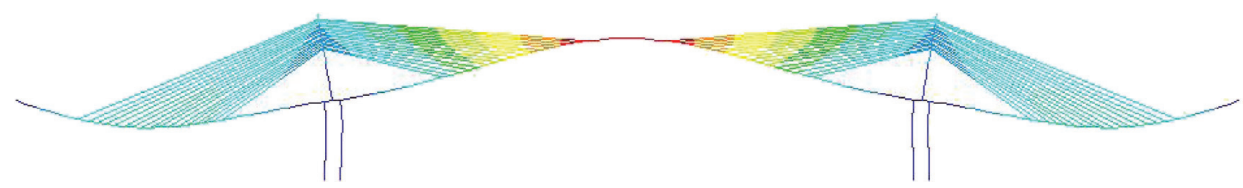

(b)

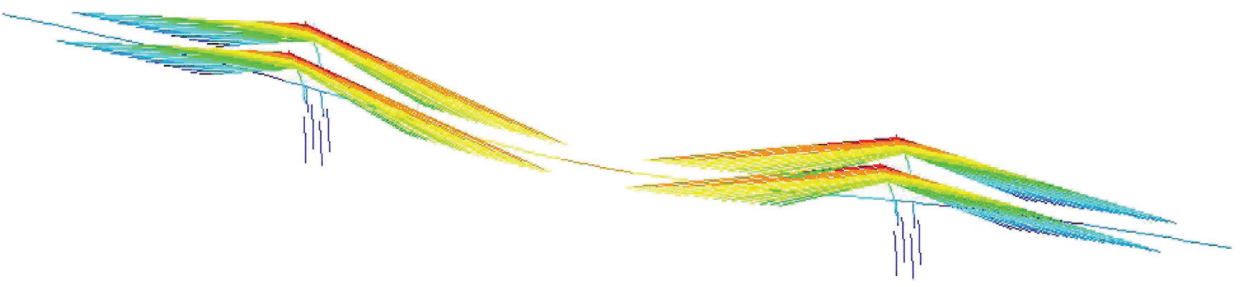

(c)

FIGURE 7: The first 3 modal shapes of the bridge: (a) $1^{\text {st }}$ order; (b) $2^{\text {nd }}$ order; and (c) $3^{\text {rd }}$ order.

$1.62 \times 10^{8} \mathrm{~N} / \mathrm{m}$. Figure 8 shows the displacement response of the simplified model and the FE model subjected to 2 recorded earthquakes. It can be observed that the dynamic responses of the two models are in satisfying agreement.

3.3. Selection of Earthquakes. According to the seismic design code of China [43], three earthquakes are adequate for time history analysis of an infrastructure. In order to fully consider the uncertainties of ground motions, a group of 20 seismic records (as listed in Table 4) are obtained from Pacific Earthquake Engineering Research Center (PEER). Peak accelerations are set to 139 gal, in accordance with the geological report and design manual of the bridge.

\section{Optimization of the APTMD with Genetic Algorithm}

In order to evaluate the vibration control effectiveness of the proposed APTMD, the vibration reduction ratio is defined as

$$
\eta_{d}=\frac{D_{0}-D_{\mathrm{ctrl}}}{D_{0}}
$$

where $D_{0}$ and $D_{\text {ctrl }}$ are the average value of the relative displacement of the bridge deck without and with damper and $\eta_{d}$ is the vibration reduction ratio of the displacement.

There are three parameters to be determined to achieve the optimal design of the APTMD, that is, the left gap, $g p_{l}$, right gap, $g p_{r}$, and the frequency ratio, $f_{d}$. The genetic algorithm is employed to obtain the optimum values of these parameters. The displacement reduction ratio $\eta_{d}$ is defined as the objective function or fitness function of the genetic algorithm. The three parameters $g p_{l}, g p_{r}$, and $f_{d}$ are the optimal variables. The range of $g p_{l}$ and $g p_{r}$ is from $0.005 \mathrm{~m}$ to $0.1 \mathrm{~m}$ at an interval of $0.005 \mathrm{~m}$. The range of $f_{d}$ is from 0.5 to 1.5 at an interval of 0.05 . Other parameters of the genetic algorithm, such as reproduction coefficient, mutation coefficient, crossover coefficient are set to the default value. The optimal individual of the final population yields the optimum APTMD: $g p_{l}=0.03 \mathrm{~m}, g p_{r}=0.09 \mathrm{~m}$, and $f_{d}=1$. 


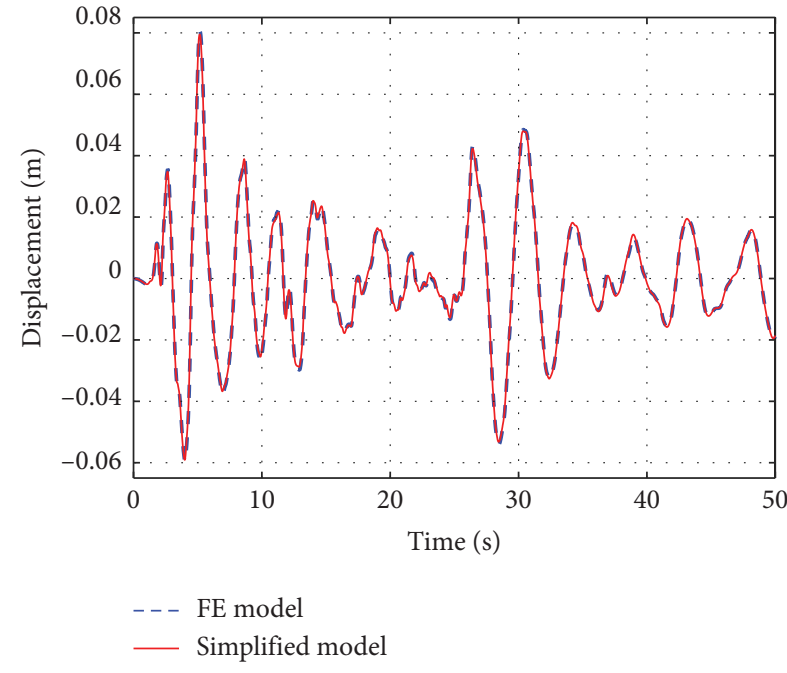

(a)

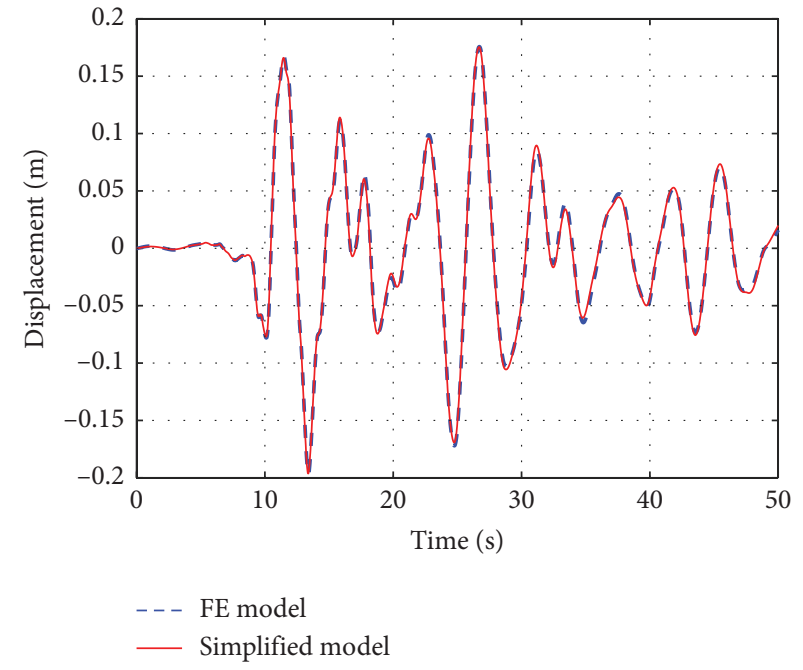

(b)

FIGURE 8: Comparison of dynamic responses computed by the simplified model and FE model: (a) displacement under El Centro earthquake and (b) displacement under Kobe earthquake.

TABLE 4: Selected ground motions.

\begin{tabular}{|c|c|c|c|c|}
\hline \multirow{2}{*}{ Number } & \multicolumn{3}{|c|}{ Earthquake } & \multirow{2}{*}{ Station } \\
\hline & Name & Magnitude & Year & \\
\hline 1 & San Fernando & 6.6 & 1971 & Pacoima Dam \\
\hline 2 & Coyote Lake & 5.7 & 1979 & Gilroy Array \#6 \\
\hline 3 & Imperial Valley-06 & 6.5 & 1979 & El Centro Array \#4 \\
\hline 4 & Imperial Valley-06 & 6.5 & 1979 & El Centro Array \#10 \\
\hline 5 & Mammoth Lakes-06 & 5.9 & 1980 & Long Valley Dam \\
\hline 6 & Irpinia, Italy-01 & 6.9 & 1980 & Sturno \\
\hline 7 & Morgan Hill & 6.2 & 1984 & Gilroy Array \#6 \\
\hline 8 & N. Palm Springs & $6.1 \mathrm{a}$ & 1986 & North Palm Springs \\
\hline 9 & Whittier Narrows-01 & 6.0 & 1987 & LB-Orange Ave \\
\hline 10 & Loma Prieta & 6.4 & 1989 & Gilroy Array \#2 \\
\hline 11 & Loma Prieta & 6.4 & 1989 & Saratoga-Aloha Ave \\
\hline 12 & Erzincan, Turkey & 6.7 & 1992 & Erzincan \\
\hline 13 & Landers & 7.3 & 1992 & Lucerne \\
\hline 14 & Northridge-01 & 6.7 & 1994 & LA Dam \\
\hline 15 & Northridge-01 & 6.7 & 1994 & Rinaldi Receiving Station \\
\hline 16 & Kobe, Japan & 6.9 & 1995 & Takarazuka \\
\hline 17 & Kobe, Japan & 6.9 & 1995 & Takatori \\
\hline 18 & Kocaeli, Turkey & 7.5 & 1999 & Gebze \\
\hline 19 & Chi-Chi, Taiwan & 7.6 & 1999 & TCU075 \\
\hline 20 & Chi-Chi, Taiwan & 7.6 & 1999 & TCU076 \\
\hline
\end{tabular}


An optimal PTMD is also designed to compare the vibration control effectiveness. The PTMD has two parameters to be designed, that is, the gap and the frequency ratio. This parameter is optimized by an enumeration algorithm. The value of the gap varies from $0.005 \mathrm{~m}$ to $0.1 \mathrm{~m}$ at an interval of $0.005 \mathrm{~m}$. The range of $f_{d}$ is from 0.5 to 1.5 at an interval of 0.05 . The optimized gap and frequency ratio are $0.095 \mathrm{~m}$ and 1 , respectively.

Considering that the TMD, the PTMD, and the APTMD all belong to the dynamic absorber family, these dampers shall be installed at the place where the largest motion occurs to achieve the best vibration control effectiveness. As shown in Figure 7, the largest motion happens at the deck of the bridge. Therefore, the dampers shall be installed inside the hollowed girder, which is spacious to accommodate these dampers.

\section{Performance Evaluation of APTMD System}

In order to validate the vibration control effectiveness of the APTMD, the seismic responses of the following systems are compared:

\section{(i) Undamped bridge}

(ii) Bridge equipped with TMD

(iii) Bridge equipped with symmetric PTMD $\left(g p=0.095 \mathrm{~m}, f_{d}=1\right)$

(iv) Bridge equipped with APTMD $\left(g p_{l}=0.03 \mathrm{~m}\right.$, $\left.g p_{r}=0.09 \mathrm{~m}, f_{d}=1\right)$

For these damping systems, the mass ratio $\mu$ is all set to $5 \%$, since increasement of mass ratio can slightly improve the vibration control effectiveness, after a certain value (normally 3\%), as previous studies revealed [30, 39]. The damping ratio and frequency ratio of the TMD is determined using the following equations [14]:

$$
\begin{aligned}
f_{\mathrm{TMD}} & =\frac{1}{1+\mu}, \\
\xi_{\mathrm{TMD}} & =\sqrt{\frac{3 \mu}{8(1+\mu)}}
\end{aligned}
$$

in which $f_{\mathrm{TMD}}$ and $\xi_{\mathrm{TMD}}$ are the frequency ratio and the damping ratio of the TMD. The pounding stiffness $\beta$ and restitution coefficient $e$ are set to $17259 \mathrm{~N} / \mathrm{m}^{1.5}$ and 0.2 based on experimental data of a previous study [30].

Figure 9-11 present the seismic response of the bridge under the Kobe earthquake. Due to the length limitation of the paper, the dynamic response corresponding to other ground motions is not plotted. The reduction ratios are listed in Table 5. It can be observed from these figures that all three dampers can effectively suppress the displacement, shear force, and bending moment of the bridge. However, the acceleration response is not satisfyingly reduced. The vibration reduction efficiency of the APTMD is slightly better than TMD and symmetric PTMD.

Considering that the ground motions are with unignorable uncertainties, the bridges are subjected to 20 ground motions and the average vibration reduction ratios are listed in Table 5. This table also demonstrates the effectiveness of the TMD, symmetric PTMD, and APTMD. In terms of the maximum displacement, shear force, and bending moment, the vibration reduction ratios of these three dampers are very close. In terms of the root mean square (RMS) value of these responses, the APTMD is better than the TMD and PTMD.

\section{Conclusions}

In this paper, a novel damping device, the asymmetric pounding tuned mass damper, is proposed to control the seismic-induced vibrations of a cable-stayed bridge. Compared with traditional symmetric PTMD, the APTMD has unsymmetrical gaps to be designed. A simplified model of the APTMD damping system with sufficient computation efficiency is established to enable optimization. GA is utilized in this paper to search for the optimal gaps and frequency ratio. Finally, time history analysis is conducted on the FE model of the bridge using ANSYS. Based on the numerical results, the following findings can be concluded:

(1) The SDOF model can simulate the behavior of the cable-stayed bridge under earthquakes with satisfying accuracy and efficiency. Computation-intense tasks such as parametric study or optimization can be performed with this model.

(2) The vibrations of the bridge are effectively mitigated by TMD, symmetric PTMD, and APTMD, indicating that impact damping can provide sufficient energy dissipation. Moreover, the impact damping is simple in design, installation, and maintenance, compared with other damping elements such as viscous dampers, SMA dampers, and eddy-current dampers. Therefore, the PTMD and APTMD are very promising for practical applications.

(3) In this paper, the left-side gap, right-side gap, and frequency ratio were selected as the parameters to be designed. These parameters are optimized using GA. The vibration reduction ratio of the optimized APTMD is slightly better than the traditional symmetric PTMD. 


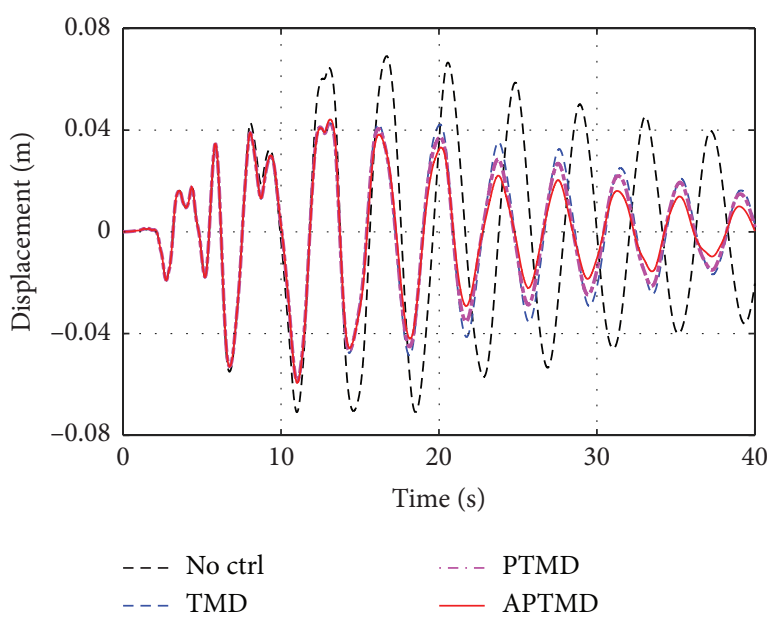

(a)

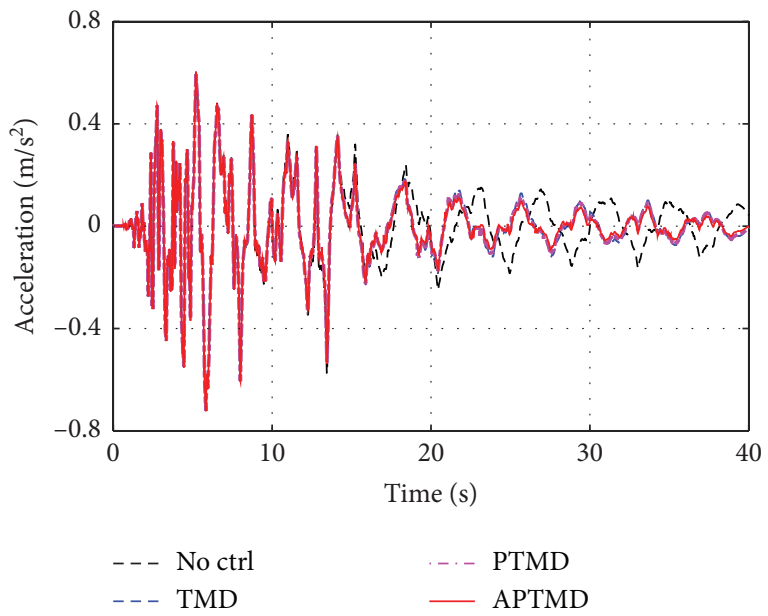

(b)

FIGURE 9: Seismic response at the midspan of the bridge when subjected to Kobe earthquake: (a) displacement and (b) acceleration.

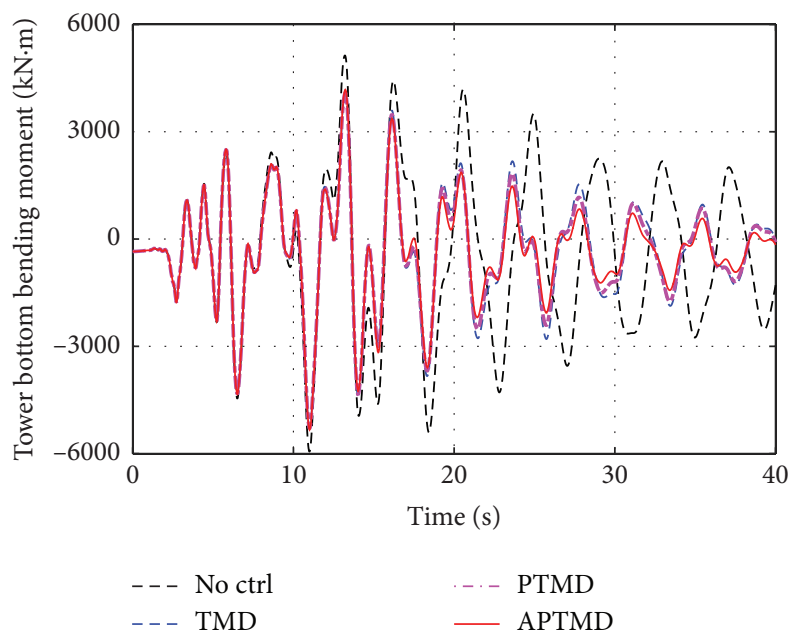

(a)

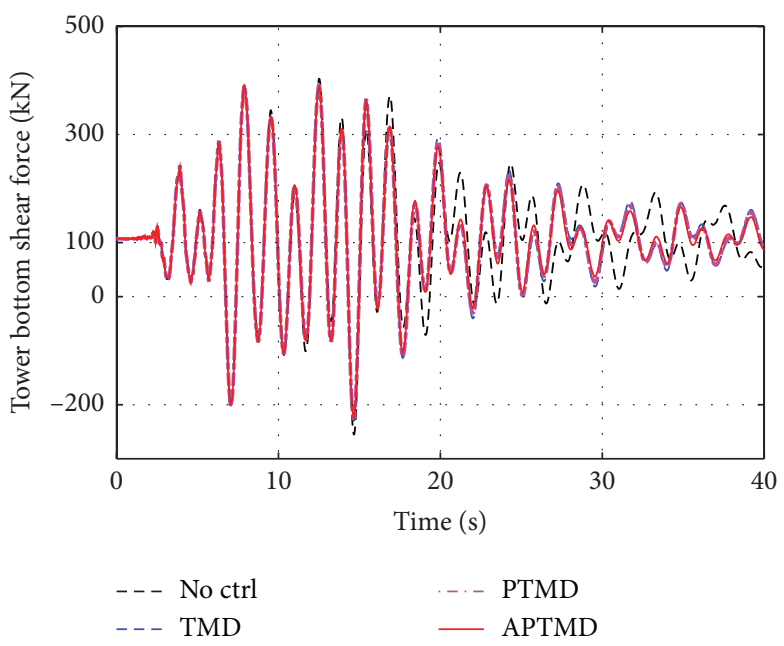

(b)

FIGURE 10: Seismic response at the bottom of the pylon when subjected to Kobe earthquake: (a) bending moment and (b) shear force. 


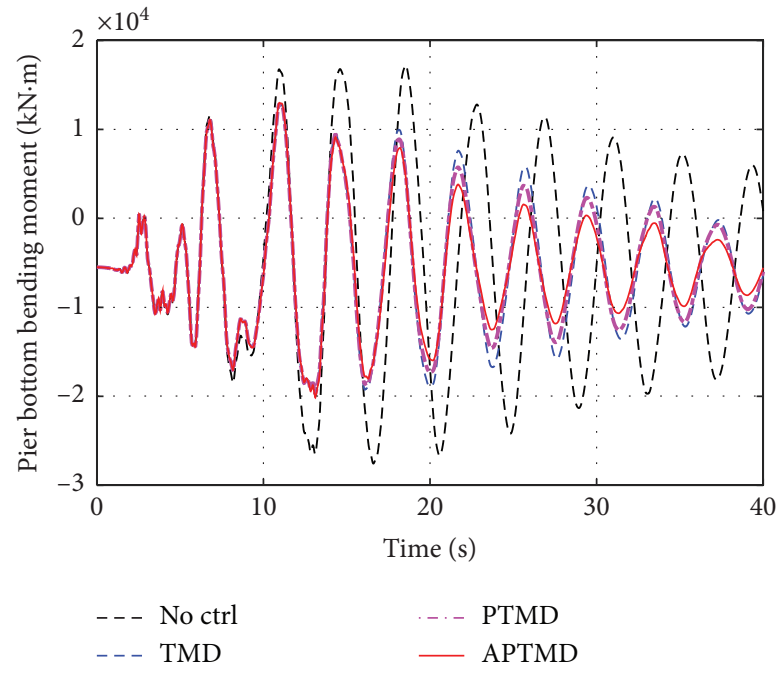

(a)

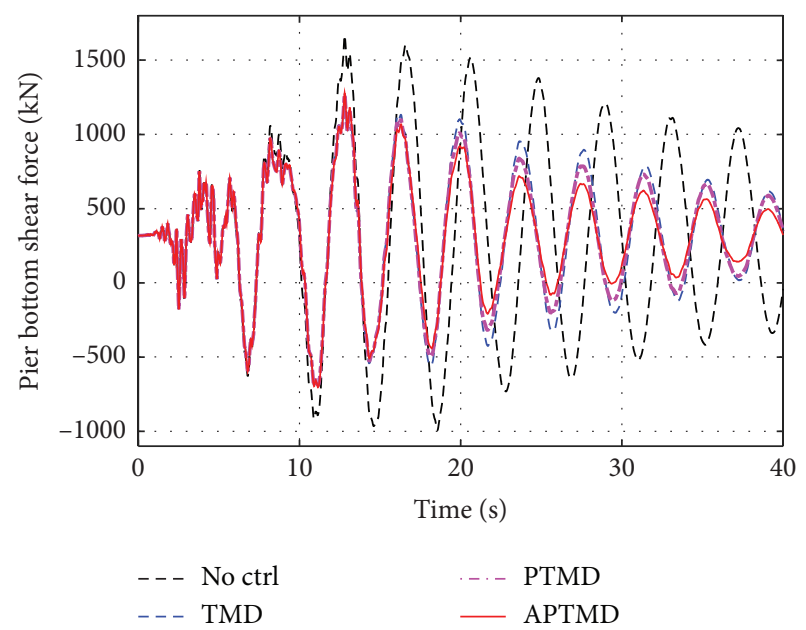

(b)

Figure 11: Seismic response at the bottom of the pier when subjected to Kobe earthquake: (a) bending moment and (b) shear force.

TABLE 5: Vibration reduction ratio of different damping systems.

\begin{tabular}{|c|c|c|c|c|c|c|}
\hline \multirow{2}{*}{ Structural response } & \multicolumn{3}{|c|}{ Peak value } & \multicolumn{3}{|c|}{ R.M.S. value } \\
\hline & TMD & PTMD & APTMD & TMD & PTMD & APTMD \\
\hline Midspan displacement & $14.70 \%$ & $15.52 \%$ & $15.65 \%$ & $21.13 \%$ & $27.80 \%$ & $37.65 \%$ \\
\hline Midspan acceleration & $-0.03 \%$ & $-0.03 \%$ & $-0.48 \%$ & $3.89 \%$ & $4.68 \%$ & $5.35 \%$ \\
\hline Shear force at pylon bottom & $1.51 \%$ & $1.66 \%$ & $1.89 \%$ & $0.86 \%$ & $1.35 \%$ & $2.01 \%$ \\
\hline Shear force at pier bottom & $20.80 \%$ & $20.85 \%$ & $20.52 \%$ & $21.18 \%$ & $23.75 \%$ & $26.77 \%$ \\
\hline Bending moment at pylon bottom & $9.52 \%$ & $9.51 \%$ & $9.26 \%$ & $26.20 \%$ & $28.87 \%$ & $31.81 \%$ \\
\hline Bending moment at pier bottom & $28.29 \%$ & $28.23 \%$ & $28.46 \%$ & $21.42 \%$ & $24.00 \%$ & $27.03 \%$ \\
\hline Bending moment at the junction of pier and beam & $26.48 \%$ & $26.46 \%$ & $26.52 \%$ & $20.31 \%$ & $22.69 \%$ & $25.44 \%$ \\
\hline
\end{tabular}

\section{Data Availability}

The data used to support the findings of this study are available from the corresponding author upon request.

\section{Conflicts of Interest}

The authors declare that there are no conflicts of interest regarding the publication of this paper.

\section{Acknowledgments}

This research was funded by National Natural Science Foundation of China (no. 51808092) and the United Navigation Foundation of Liaoning Province (No. 2020-HYLH48). The financial supports are gratefully acknowledged.

\section{References}

[1] W. Guo, "Seismic performance evaluation of typical piers of China's high-speed railway bridge line using pushover analysis," Mathematical Problems in Engineering, vol. 2019, Article ID 9514769, 17 pages, 2019.

[2] X. Liu and Y. Wang, "A novel seismic risk analysis method for structures with both random and convex set mixed variables: case study of a RC bridge," Mathematical Problems in Engineering, vol. 2019, Article ID 3613651, 14 pages, 2019.

[3] K. Meng, "A new approach for longitudinal vibration of a large-diameter floating pipe pile in visco-elastic soil considering the three-dimensional wave effects," Computers and Geotechnics, vol. 128, Article ID 103840, 2020.

[4] K. Meng, C. Cui, and H. Li, “An ontology framework for pile integrity evaluation based on analytical methodology," IEEE Access, vol. 8, pp. 75158-75168, 2020.

[5] Y. Peng and T. Huang, "Sliding implant-magnetic bearing for adaptive seismic mitigation of base-isolated structures," Structural Control and Health Monitoring, vol. 26, no. 10, 2019.

[6] Y. Peng, T. Huang, and J. Chen, "Experimental study of seismic isolated structures with sliding implant-magnetic bearings," Journal of Earthquake Engineering, vol. 23, pp. 1-32, 2020.

[7] Y. Peng, "Experimental study of sliding hydromagnetic isolators for seismic protection," Journal of Structural Engineering (United States), vol. 145, no. 5, 2019.

[8] W. Zheng, "Parametric study of superelastic-sliding LRB system for seismic response control of continuous bridges," Journal of Bridge Engineering, vol. 9, no. 25, 2020.

[9] D. De Domenico, E. Gandelli, and V. Quaglini, "Adaptive isolation system combining low-friction sliding pendulum 
bearings and SMA-based gap dampers," Engineering Structures, vol. 212, Article ID 110536, 2020.

[10] B. Wang, S. Zhu, and F. Casciati, "Experimental study of novel self-centering seismic base isolators incorporating superelastic shape memory alloys," Journal of Structural Engineering, vol. 146, Article ID 040201297, 2020.

[11] W. Zheng, H. Wang, J. Li, and H. Shen, "Performance evaluation of bridges isolated with SMA-based friction pendulum system at low temperatures," Soil Dynamics and Earthquake Engineering, vol. 125, Article ID 105734, 2019.

[12] W.-Z. Zheng, H. Wang, J. Li, and H.-J. Shen, "Parametric study of SMA-based friction pendulum system for response control of bridges under near-fault ground motions," Journal of Earthquake Engineering, vol. 12, pp. 1-19, 2019.

[13] S. Gur, G. N. Frantziskonis, and S. K. Mishra, "Thermally modulated shape memory alloy friction pendulum (tmSMA-FP) for substantial near-fault earthquake structure protection," Structural Control and Health Monitoring, vol. 24, no. 11, p. e2021, 2017.

[14] R. Rana and T. T. Soong, "Parametric study and simplified design of tuned mass dampers," Engineering Structures, vol. 20, no. 3, pp. 193-204, 1998.

[15] J. Jiang, S. Ho, N. J. Markle, N. Wang, and G. Song, "Design and control performance of a frictional tuned mass damper with bearing-shaft assemblies," Journal of Vibration and Control, vol. 25, no. 12, pp. 1812-1822, 2019.

[16] E. Matta, "A novel bidirectional pendulum tuned mass damper using variable homogeneous friction to achieve amplitude-independent control," Earthquake Engineering \& Structural Dynamics, vol. 48, no. 6, pp. 653-677, 2019.

[17] S. Liu, "Shaking table test and numerical simulation of eddycurrent tuned mass damper for structural seismic control considering soil-structure interaction," Engineering Structures, vol. 212, Article ID 110531, 2020.

[18] X. Lu, Q. Zhang, W. Wu, and J. Shan, "Data-driven two-level performance evaluation of eddy-current tuned mass damper for building structures using shaking table and field testing," Computer-Aided Civil and Infrastructure Engineering, vol. 34, no. 1, pp. 38-57, 2019.

[19] L. Wang, "Study on adaptive-passive eddy current pendulum tuned mass damper for wind-induced vibration control," Structural Design of Tall and Special Buildings, vol. 29, no. 15, 2020.

[20] Z. Wang, "Optimization design and model tests for a pendulum eddy-current tuned mass damper TMD," Zhendong Yu Chongil Journal of Vibration and Shock, vol. 37, no. 9, pp. 1-7, 2018.

[21] H. Gao, H. Wang, J. Li et al., "Optimum design of viscous inerter damper targeting multi-mode vibration mitigation of stay cables," Engineering Structures, vol. 226, Article ID 111375, 2021.

[22] R. Ma, K. Bi, and H. Hao, "Heave motion mitigation of semisubmersible platform using inerter-based vibration isolation system (IVIS)," Engineering Structures, vol. 219, Article ID 110833, 2020.

[23] H. Zuo, "Influences of ground motion parameters and structural damping on the optimum design of inerter-based tuned mass dampers," Engineering Structures, vol. 227, Article ID 111422, 2021.

[24] K. Xu, K. Bi, Q. Han, X. Li, and X. Du, "Using tuned mass damper inerter to mitigate vortex-induced vibration of longspan bridges: analytical study," Engineering Structures, vol. 182, pp. 101-111, 2019.

[25] Z. Lu, X. Chen, and Y. Zhou, "An equivalent method for optimization of particle tuned mass damper based on experimental parametric study," Journal of Sound and Vibration, vol. 419, pp. 571-584, 2018.

[26] K. Rong and Z. Lu, "An improved esm-fem method for seismic control of particle tuned mass damper in mdof system," Applied Acoustics, vol. 172, 2021.

[27] L. Tian, "Seismic response control of transmission tower-line system using SMA-based TMD," Structural Engineering and Mechanics, vol. 74, no. 1, pp. 129-143, 2020.

[28] N. D. Tiwari, "A shape memory alloy-tuned mass damper inerter system for passive control of linked-SDOF structural systems under seismic excitation," Journal of Sound and Vibration, vol. 494, Article ID 115893, 2021.

[29] M. R. Ghasemi, N. Shabakhty, and M. H. Enferadi, "Vibration control of offshore jacket platforms through shape memory alloy pounding tuned mass damper (SMA-PTMD)," Ocean Engineering, vol. 191, Article ID 106348, 2019.

[30] P. Zhang, G. Song, H.-N. Li, and Y.-X. Lin, "Seismic control of power transmission tower using pounding TMD," Journal of Engineering Mechanics, vol. 139, no. 10, pp. 1395-1406, 2013.

[31] L. Tian and X. Gai, "Wind-induced vibration control of power transmission tower using pounding tuned mass damper," Journal of Vibroengineering, vol. 17, no. 7, pp. 3693-3701, 2015.

[32] W. Lin, "Shaking table test of pounding tuned mass damper (PTMD) on a frame structure under earthquake excitation," Computers and Concrete, vol. 20, no. 5, pp. 545-553, 2017.

[33] J. Jiang, "Experimental studies on the effectiveness and robustness of a pounding tuned mass damper for vibration suppression of a submerged cylindrical pipe," Structural Control and Health Monitoring, vol. 24, no. 12, p. e2027, 2017.

[34] G. B. Song, "Vibration control of a pipeline structure using pounding tuned mass damper," Journal of Engineering Mechanics, vol. 142, no. 6, p. 1, 2016.

[35] X. Yin, G. Song, and Y. Liu, "Vibration suppression of wind/ traffic/bridge coupled system using multiple pounding tuned mass dampers (MPTMD)," Sensors, vol. 19, no. 5, p. 1133, 2019.

[36] X. Yin, "Suppression of bridge vibration induced by moving vehicles using pounding tuned mass dampers," Journal of Bridge Engineering, vol. 23, no. 7, 2018.

[37] W. Wang, X. Wang, X. Hua, G. Song, and Z. Chen, "Vibration control of vortex-induced vibrations of a bridge deck by a single-side pounding tuned mass damper," Engineering Structures, vol. 173, pp. 61-75, 2018.

[38] H. Li, "Robustness study of the pounding tuned mass damper for vibration control of subsea jumpers," Smart Materials and Structures, vol. 24, Article ID 0950019, 2015.

[39] P. Zhang, "Parametric study of pounding tuned mass damper for subsea jumpers," Smart Materials and Structures, vol. 25, no. 1, Article ID 015028, 2015.

[40] W. Wang, "Optimum design of a novel pounding tuned mass damper under harmonic excitation," Smart Materials and Structures, vol. 26, 2017.

[41] W. Wang, X. Hua, X. Wang, Z. Chen, and G. Song, "Numerical modeling and experimental study on a novel pounding tuned mass damper," Journal of Vibration and Control, vol. 24, no. 17, pp. 4023-4036, 2017.

[42] R. Jankowski, "Non-linear viscoelastic modelling of earthquake-induced structural pounding," Earthquake Engineering \& Structural Dynamics, vol. 34, no. 6, pp. 595-611, 2005.

[43] Mohurd and Aqsiq, Code for Seismic Design of Buildings in GB 50011-2010, China Architecture \& Building Press, Beijing, China, 2016. 